International Journal of Applied Chemistry.

ISSN 0973-1792 Volume 17, Number 1 (2021) pp. 55-67

(C) Research India Publications

https://dx.doi.org/10.37622/IJAC/17.1.2021.55-67

\title{
Fabrication of zirconyl chloride doped polyvinyl alcohol / polythiophene (PVA-Zr-PTh) nanocomposite thin films by chemical polymerization method
}

\author{
Anand Patil*, Nirdosh Patil ${ }^{1}$ \\ ${ }^{1}$ Department of Chemistry, Sharnbasva University, Vidya Nagar, Kalaburagi, \\ Karanataka-585 103, India \\ *Department of Chemistry, P D A College of Engineering, Eiwan-E-shahi Road, \\ Kalaburagi, Karnataka-585 103, India
}

\begin{abstract}
Zirconyl chloride doped polyvinyl alcohol / polythiophene (PVA-Zr-PTh) nanocomposite thin films by chemical polymerization method. Zirconyl chloride $\mathrm{ZrOCl}_{2} .8 \mathrm{H}_{2} \mathrm{O}$ was used at different concentrations as doping $(0,0.1$, $0.2,0.3,0.4,0.6,0.7$ and $0.8 \mathrm{~g})$. The produced films were characterized by $\mathrm{X}$ ray diffraction (XRD), UV- Visible spectroscopy, Infrared spectroscopy (IR), scanning electron microscope (SEM), transmission electron microscopy (TEM), d.c electrical conductivity and dielectric constant measurements. The optical properties of all investigated films were studied, where the optical absorption of the prepared films decreases with increasing the amount of $\mathrm{ZrOCl}_{2} .8 \mathrm{H}_{2} \mathrm{O}$ in both VIS $(500-700 \mathrm{~nm})$ and UV $(200-400 \mathrm{~nm})$ regions. It is clear from the XRD patterns of the PVA-Zr-PTh samples that the intensity of the diffraction peaks increases with the increase in zirconylchloride concentration due to the semicrystalline nature of the resulting $\mathrm{Zr}$ (IV) doped PVA/PTh compositions. These results are also in good agreement with the morphological changes observed in the PVA-Zr-PTh samples, as per the SEM and TEM analysis, The increase in conductivity with increase in $\mathrm{Zr}(\mathrm{IV})$ concentration up to $0.8 \mathrm{~g}$ of $\mathrm{ZrOCl}_{2} .8 \mathrm{H}_{2} \mathrm{O}$ has been observed in PVA-Zr-PPy composites and the dielectric constant tends to increase with the increment in frequency as well as with enhancement in $\operatorname{Zr}(\mathrm{IV})$ composition.
\end{abstract}

Keywords: X-ray diffraction, Zirconyl chloride, composites, optical, conductance 


\section{INTRODUCTION:}

Conductive polymers (CPs) such as polyaniline (PANi), polypyrrole (PPy), polythiophene (PTh) and their derivatives such as carbon- substitute supports for fuel cell catalysts have received a considerable attention from researchers due to their suitable features like good electronic and proton conductivity, high surface area, suitable porosity, high stability, nontoxic effects and good resistance to corrosion in fuel cell operating con- ditions [1,2]. Right around countless engaging conducting polymers, polythiophene has been quite compelling because of its wide range of electrochemical activity, higher electrical conductivity, improved mechanical properties, elevated charge transporter portability and different suitable headlines. Polythiophene can be viewed as a conjugated chain consisting of $\operatorname{sp}^{2} \mathrm{p}_{x}$-carbon atoms which have an analogous structure to cis-polyacetylenes and are stabilized by sulfur atoms. The relatively high polarizability of the sulfur atoms in the thiophene backbone will also influence the properties of a polythio- phene. The lone pair of electrons on the polarized sulfur atom of thiophene allows them to readily bind to heavy metal ions. Thus, sulfur atoms would be the main sites for heavy metal ions [36]. However, on the basis of the histogram dis- playing the number of papers reporting PAni, PPy and PTh in ref. [2], few reports were studied on the usage of PTh as a catalyst support, whereas most of the reports belong to its derivatives such as poly(3-methylthiophene) (PMT) and poly(3,4-ethylenedioxythiophene) (PEDOT) [79]. In the vast field of materials science, recently the studies on nanocomposites have drawn great attention because the prop- erties of composite materials can display synergistic improve ments with respect to the individual components [10]. Although the presence of sulfur atoms in the polythiophene chains imparts high-affinity towards heavy metal ions, they may cause Pt particle aggregation [11]. However, inorder to solve the limitations on their solubility and electrochemical properties of the conductive PANI composites, which are mainly due to the polymerization ways, non homogeneous composite formation, and doping-de doping properties of the conducting polymers, it is necessary to develop a real composite of conductive polymers with the essential properties of the conductive polymers in addition to the improved processibility and mechanical properties. Improvement of these properties can be achieved either by forming copolymers of pyrrole or by forming PPY composites or blends with commercially available polymers or inorganic materials which offer better mechanical and optical properties, stability and process ability [12] so polypyrrole combines with an insulating polymer has superior mechanical properties[13]. The polymer composites can be prepared either by electrochemical or chemical polymerization. Inorganic additives such as transition metal salts have considerable effect on the optical and electrical properties of PVA polymer[14].

Polythiophene has been widely used in environmentally and thermally stable conjugated polymer materials, such as chemical and optical sensors, light-emitting diodes and displays, photovoltaic devices, molecular devices, DNA detection, polymer electronic interconnects, solar cells and transistors. In the present study PVA is incorporated that acts as host material in the conducting composite polymer containing polythiophene (PTh). In this work, the polyvinyl alcohol was used as 
insulating polymer and combined with PTh by using chemical polymerization to improve the properties of PTh. The concentration of the doping namely hydrous zirconyl chloride was varied in order to investigate the influence of doping compositions on structure, optical and electrical properties of the composite polymer.

\section{EXPERIMENTAL:}

\section{Characterization}

Thiophene monomer, anhydrous iron(III) chloride (FeCl3), polyvinyl alcohol (PVA), $\mathrm{ZrOCl}_{2} 8 \mathrm{H}_{2} \mathrm{O}$ and methanol from SD Fine Chemicals (AR grade) were used in the present study. The thiophene monomer was used as received. Composite PTh/PVA prepared according to by chemical oxidative polymerization method. These synthesized PVA-Zr-PTh composite films with various content of $\mathrm{Zr}(\mathrm{IV})$, For these films morphology and the structures were studied using scanning electron microscopy (SEM, JSM-6360LV, Japan) and by transmission electron microscopy (TEM) JEOL JEM-1230 operating at $120 \mathrm{kV}$. The X-ray diffraction patterns of the powders were taken using Philips XPERT diffractometer using $\mathrm{Cu} \mathrm{K \alpha}$ radiation $\left(\lambda=1.54 \mathrm{~A}^{\circ}\right)$. The chemical bonding was analyzed by using FTIR - Perkin Elmer make-model Spectrum RXI spectroscopy. UV-Visible measurements were carried out on Perkin Elmer make-Lambada 35 model and absorption spectra were obtained by depositing the film PVA-Zr-PTh on glass substrate The AC conductivity of all the composites with different $\mathrm{Fe}_{2} \mathrm{O}_{3}$ content was studied in the frequency range of 0.2 to $10 \mathrm{MHz}$ using LCR-Q meter (Wayne Kerr, 4300) analyzer

\section{Preparation of Zr-doped PVA/PTh composites}

The Zr-doped PVA/PTh composites were synthesized by in situ polymerization where the thiophene and zirconyl chloride is dispersed in PVA matrix. PVA with molecular weight of $10000 \mathrm{~g} / \mathrm{mol}$ was used as the basic polymeric materials in this work. $1 \mathrm{~g}$ of PVA powder was added to doubly distilled water and allowed to swell for $24 \mathrm{~h}$ at room temperature. The polymeric solution is continuous stirring in magnetic stirrer. In another beaker, two milliliter of thiophene was dissolved in $70 \mathrm{ml} \mathrm{CHCl}_{3}$ and 9.0 grams of $\mathrm{FeCl}_{3}$ was weighed and added to $180 \mathrm{ml} \mathrm{CHCl}_{3}$ solution. This solution was stirred using magnetic stirrer and mixed with solution of PVA. The mixture was further stirred for $10 \mathrm{~min}$. Finally, $0.1 \mathrm{~g}$ zirconyl chloride were used as a doping in the composite mixture and stirred further for $10 \mathrm{~min}$. Different amounts of zirconyl chloride salt $(0.2,0.3,0.4,0.50 .60 .7$ and $0.8 \mathrm{~g})$ were added as stated above, so different samples were prepared. The whole reaction mixture was homogenized and kept in a petri dish (corning glass, $2.5^{\prime \prime}$ diameter) maintained at $35 \pm 0.2^{\circ} \mathrm{C}$ for $24 \mathrm{~h}$.

\section{RESULTS AND DISCUSSION}

\section{FTIR spectroscopic studies}

The FTIR spectrum exhibited characteristic peaks in the range of $3469 \mathrm{~cm}^{-1}-3490$ $\mathrm{cm}^{-1}$ due to $\mathrm{O}-\mathrm{H}$ stretching frequency of PVA / PTh blend, but in the infra red 
spectra of PVA-Zr-PTh composites films these absorption bands were absent in all composite films of PVA-Zr-PTh due to coordination of $\mathrm{OH}$ group of PVA to $\mathrm{Zr}(\mathrm{IV})$ ion via deprotonation. Major peak for $\mathrm{C}-\mathrm{H}$ stretching vibration appeared at 2915 and $2838 \mathrm{~cm}^{-1}$. The peaks at $1210 \mathrm{~cm}^{-1}$ and $1042 \mathrm{~cm}^{-1}$ were due to $\mathrm{C}-\mathrm{H}$ bending and $\mathrm{C}-\mathrm{H}$ in-plane deformation[15-16]. The peaks at $1665 \mathrm{~cm}^{-1}$ and $1405 \mathrm{~cm}^{-1}$ were attributed to $\mathrm{C}=\mathrm{C}$ asymmetric and symmetric stretching vibrations of thiophene ring respectively, In PVA-Zr-PTh samples all these bands slight shifted higher frequencies and the characteristic peak of polythiophene was found at $755 \mathrm{~cm}^{-1}(\mathrm{C}-\mathrm{S}$ bending) [17] this band also shifted to higher frequencies due to complexation through $\mathrm{S}$ of thiophene ring of PTh in PVA-Zr-PTh composite samples. Further, the vibration peaks found in the range $770-710 \mathrm{~cm}^{-1}, 550 \mathrm{~cm}^{-1}$ and $450 \mathrm{~cm}^{-1}$ can be attributed to (C-S), (M-O) and ( $\mathrm{M}-\mathrm{S})$ where $\mathrm{M}=\mathrm{Zr}(\mathrm{IV})$, which indicated that the doping zirconium ions by the formation of complexes with polymer. The appearance of bands at $1560 \mathrm{~cm}^{-1}$ is indicative of the formation of small conjugated polyene sequence which is presumably responsible for the doping of $\mathrm{Zr}^{4+}$ with PVA--PTh blend.
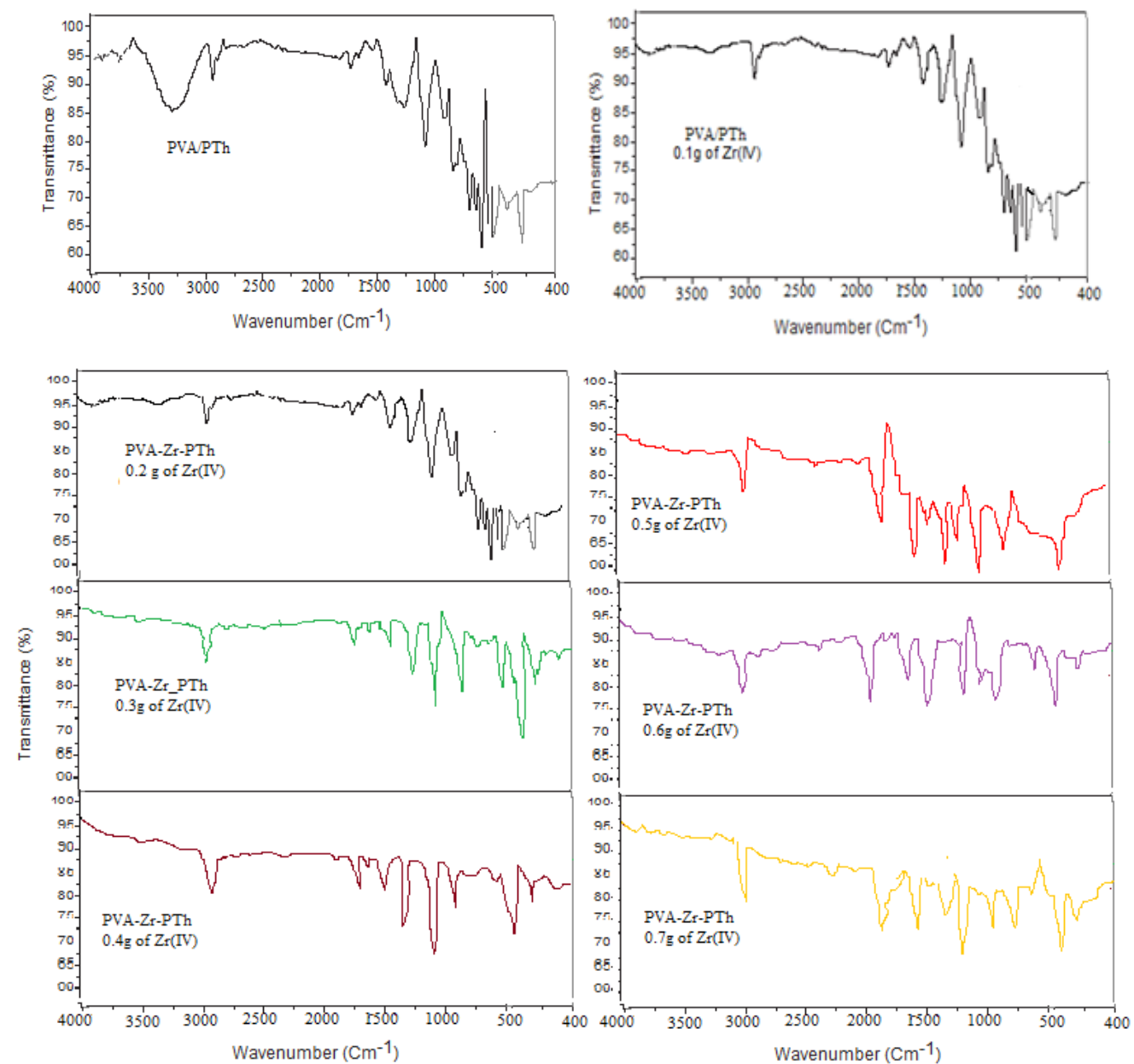

Figure.1. FTIR transmission curves of PVA/PTh and that doped with filler 0.1, 0.2, $0.3,0.4,0.5$. 0.6 and $0.7 \mathrm{~g}$ of $\mathrm{ZrOCl}_{2} 8 \mathrm{H}_{2} \mathrm{O}$ 


\section{X-ray diffraction studies}

Fig, 2 shows the XRD patterns of pure PVA/PTh and that doped with $\mathrm{ZrOCl}_{2} .8 \mathrm{H}_{2} \mathrm{O}$ salt range from $0.0,0.4,0.6$ and 0.8 . The PVA/PTh shows broad peaks around $2 \theta$ values of $25.20^{\circ}$ and $27.32^{\circ}$ indicating amorphous structure and are due to the scattering from PVA/PTh chains at the inter planar spacing. Instead of broad peaks indicating amorphous nature [18], the amorphous nature of PVA results from the strong intermolecular interaction of PVA chains through intermolecular hydrogen bonding with sulphure of thiophene ring of PTh in pure PVA-PTh composite film. After complexation with fillers $\mathrm{ZrOCl}_{2} .8 \mathrm{H}_{2} \mathrm{O}$ salt range from $0.0,0.1,0.2,0.30 .4$, $0.5,0.6$, and $0.8 \mathrm{~g}$, the PVA-Zr-PTh composite samples show intense and narrow peaks at $25.20^{\circ}$ and $27.32^{\circ}$ with additional diffraction peaks at $27.35^{\circ}$ $29.26^{0}, 32.42^{0}, 36.43^{\circ}, 42.23^{\circ}, 47.26^{\circ}, 49.59^{\circ}, 52.32^{\circ}$ and $54.25^{\circ}$ and are (100) (100) (100) (110) (110) (111) (111) (113) (200) plane orientation of Zr particles for the $0.8 \mathrm{~g}$ of zirconyl chloride as dopant. It is also observed that as concentration of zirconyl chloride increases sharpness of the peaks increase. The presence of these additional peaks is a clear evidence of the $\mathrm{Zr}^{4+}$ substitution in PVA/PTh blend and complexation through oxygen of $-\mathrm{OH}$ groups of PVA via deprotonation

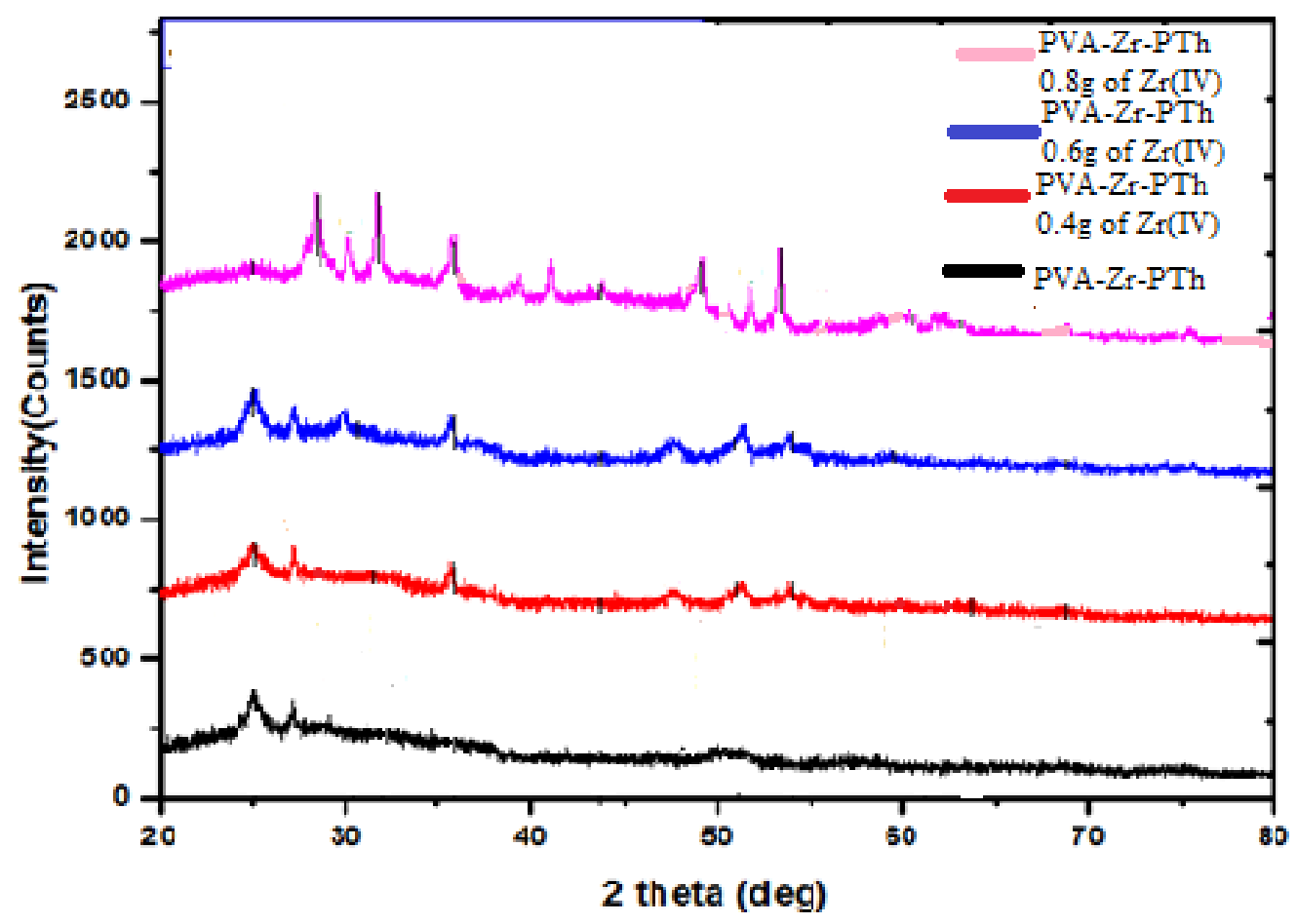

Figure 2. XRD patterns of PVA/PTh composite and that doped with filler $(0.2,0.4$, 0.6 , and $0.8 \mathrm{~g}$ of $\mathrm{ZrOCl}_{2} 8 \mathrm{H}_{2} \mathrm{O}$ ). 
and sulphur of thiophene ring. It is also observed that the PVA-Zr-PTh samples have a more crystalline and ordered structure compared to pure PVA/PTh blend which maintains the structural integrity during the substitution of $\mathrm{Zr}^{4+}$ ions in $\mathrm{PVA} / \mathrm{PTh}$ blend. The XRD peaks seen in PVA/PTh blend are weak and broad compared to the sharp and narrow diffraction peaks in the PVA-Zr-PTh samples. It is clear from the XRD patterns of the PVA-Zr-PTh samples that the intensity of the diffraction peaks increases with the increase in zirconyl concentration due to the semi crystalline nature of the resulting $\mathrm{Zr}(\mathrm{IV})$ doped PVA/PTh compositions. These results are also in good agreement with the morphological changes observed in the PVA-Zr-PTh composite films, as per the SEM and TEM analysis, described in the following sections. [19]. The peak apex is in excellent consent with JCPDS file card No.41-0254. The crystalline planes corresponding to these $2 \theta$ values of $0.8 \mathrm{~g}$ of zirconyl chloride doped PVA-Zr-PTh film were determined. They were found to be $d=3.61 \AA, 3.38 \AA, 3.07$ $\AA, 2.72 \AA, 2.36 \AA, 2.75 \AA, 2.12 \AA, 2.03 \AA, 1.93 \AA$, and $1.86 \AA$ respectively. Presently observed peak positions are comparable with those observed for pure $\mathrm{V}_{2} \mathrm{O}_{5}$ [20]. Using peak widths and by following Scherer equation given below [21].

$$
(\mathrm{D}=\mathrm{K} \lambda /(\beta \cos \theta)
$$

Where, $\mathrm{D}$ is average diameter of particles, $\lambda$ is wavelength of radiation used, $\beta$ is fullwidth half maximum of a peak observed and $\theta$ is Bragg's angle. The grain sizes of the some polymer composites films of PVA-Zr-PTh with $0.2 \mathrm{~g}$ of $\mathrm{Zr}(\mathrm{IV}) .0 .4 \mathrm{~g}$ of $\mathrm{Zr}(\mathrm{IV}), 0.6 \mathrm{~g}$ of $\mathrm{Zr}(\mathrm{IV})$ and $0.8 \mathrm{~g}$ of $\mathrm{Zr}(\mathrm{IV})$ dopants were determined to be $10.89 \mathrm{~nm}$, $6.43 \mathrm{~nm}, 4.90 \mathrm{~nm}$ and $3.15 \mathrm{~nm}$ respectively. By complexation with filler content 0.2 , 0.4, $0.6 \mathrm{~g}$ and $0.8 \mathrm{~g}$, the particle size decreases as filler content increases and excess the addition of the fillers restrict the growth of the polymerization process of PVA-ZrPTh composite. Further increase of the filler greater than $0.8 \mathrm{~g}$ the nanoparticles tend to form high agglomeration, this was confirmed by SEM and TEM,

\section{Morphology study:}

The SEM images of PVA/PTh and the few composite PVA-Zr-PTh composites with different weights of fillers $0.2,0.4,0.6$ and $0.8 \mathrm{~g}$ of $\mathrm{ZrOCl}_{2} 8 \mathrm{H}_{2} \mathrm{O}$ were shown in the figure-3. Surface morphology of the PVA-Zr-PTh samples is considerably modified by increasing the $\mathrm{Zr}(\mathrm{IV})$ concentration[22]. On increasing the $\mathrm{Zr}(\mathrm{IV})$ doping concentration to the highest level, bigger flake like structures are observed indicating uniformity in $\mathrm{Zr}(\mathrm{IV})$ distribution with in the PVA/PTh matrix. This type of more ordered structure assists the arrangement of electrically conductive network within the PVA/PTh chains leading to enhanced electron transport amongst the flakes, thus contributing to a high level of electrical conductivity. The SEM analysis shows that 
the samples become structurally more ordered with the increase in $\operatorname{Zr}(\mathrm{IV})$ concentration. The formation of these ordered structures supports the earlier conclusions on the basis of the XRD studies.
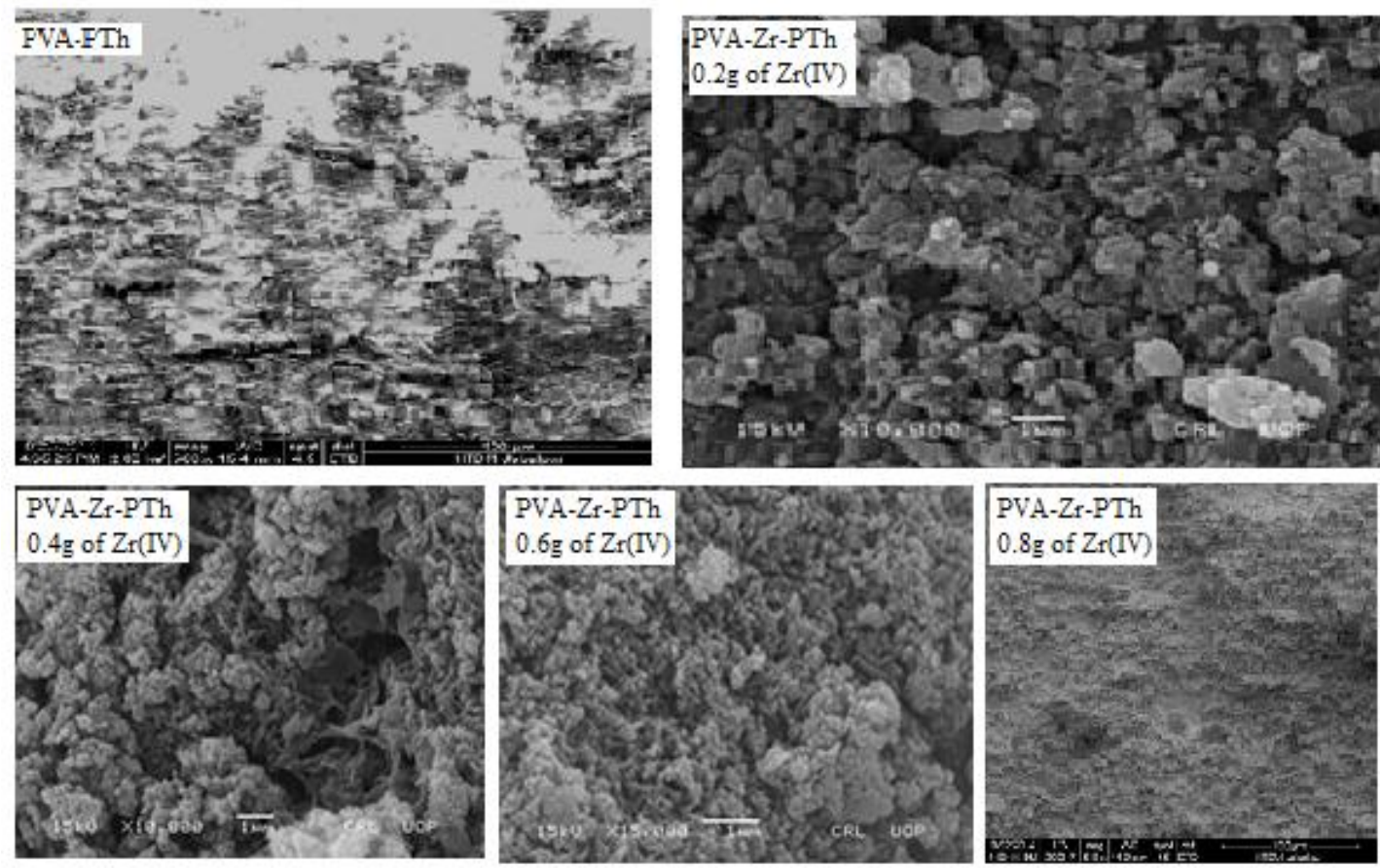

Figure.3. SEM images of PVA/PTh and that doped with filler a) PVA/PTh b) 0.2 , c) $0.4, \mathrm{~d}) 0.6$ and e) $0.8 \mathrm{~g}$ of $\mathrm{ZrOCl}_{2} 8 \mathrm{H}_{2} \mathrm{O}$ )

\section{UV-Visible absorption studies}

The UV-VIS spectra of the sample under investigation were recorded, the spectra of pure PVA/PTh and that doped with different Zirconyl chloride salt concentrations ( $0.2,0.4,0.6$ and $0.8 \mathrm{~g}$ ) is shown in Fig. 4. The optical absorption of the prepared films increases with increasing the concentration of $\mathrm{ZrOCl}_{2} .8 \mathrm{H}_{2} \mathrm{O}$ in both VIS (500-700 $\mathrm{nm})$ and UV (200-400 nm) regions, where the PVA/PTh has one spectral bands at $340 \mathrm{~nm}[23]$. The intensity of the bands increases with increasing the $\mathrm{ZrOCl}_{2} \cdot 8 \mathrm{H}_{2} \mathrm{O}$ contents providing an evidence for the incorporation of $\mathrm{Zr}^{4+}$ into PVA/PTh matrix where as their positions are slightly shifted to higher wave length (red shift). Two absorption bands observed near 282 and $350 \mathrm{~nm}$ are characteristic to the presence of octahedral structure around the $\mathrm{Zr}(\mathrm{IV})$ ion. The numerous double and single bonds as well as non bonding electrons present an electron density in the PVA/PTh composite matrix. This electron density makes the composite matrix effective for the correlation, interaction or very high vital with $\mathrm{Zr}(\mathrm{IV})$ ions by the formation of complexes and do not show d-d transitions. The bands observed in the region $275-285 \mathrm{~nm}$ and $340-$ $350 \mathrm{~nm}$ may be due to intra ligand transition and ligand to metal charge transfer(LMCT)[24] 


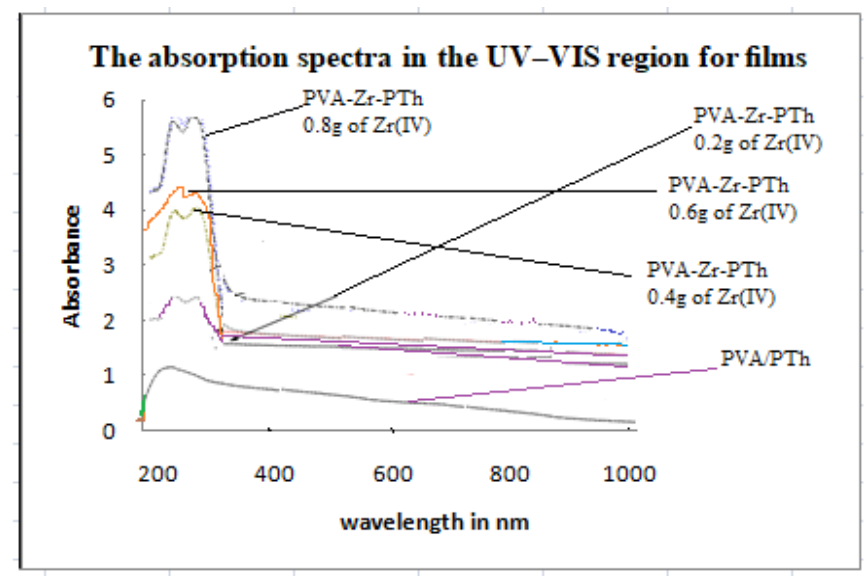

Figure 4. The absorption spectra in the UV-Visible region of various films

\section{Electrical Conductivity:}

Conductivity variation with temperature for the various composites PVA-Zr-PTh is shown in Fig.5. Conductivity increased with increasing temperature indicating semiconducting nature, these results are in agreement with that reported for other similar systems [25].

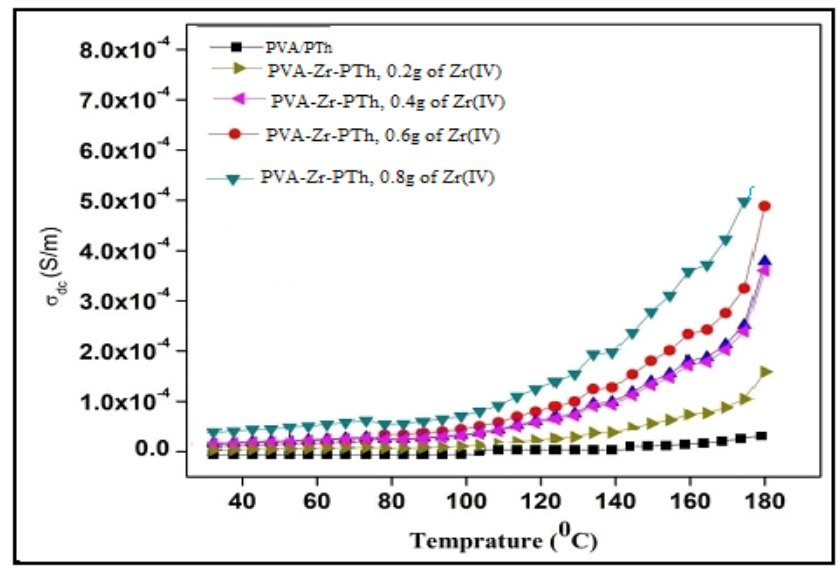

Figure 5. Temperature dependence of electrical conductivity of composites, PVA-ZrPTh. and that doped with $0.2,0.4,0.6$ and $0.8 \mathrm{~g}$ of $\mathrm{ZrOCl}_{2} .8 \mathrm{H}_{2} \mathrm{O}$

The measured room temperature conductivity for PVA/PTh, and that doped with $(0.2$, 0.4, 0.6 and $0.8 \mathrm{~g}$ of $\mathrm{ZrOCl}_{2} 8 \mathrm{H}_{2} \mathrm{O}$, PVA-Zr-PTh .composites are $0.23 \times 10^{-4}(\Omega \mathrm{m})^{-1}$, $0.20 \times 10^{-4}(\Omega \mathrm{m})^{-1}, 0.17 \times 10^{-4}(\Omega \mathrm{m})^{-1}, 0.14 \times 10^{-4}(\Omega \mathrm{m})^{-1}$ and $0.12 \times 10^{-4}(\Omega \mathrm{m})^{-1}$ respectively. These values are two orders of magnitude smaller than the reported values for individual pure PVA and PTh. This implies that conductivity increases with the incorporation of $\mathrm{Zr}^{4+}$ in PVA-PTh. The increase in conductivity with increase in $\mathrm{Zr}(\mathrm{IV})$ concentration up to $0.8 \mathrm{~g}$ of $\mathrm{ZrOCl}_{2} 8 \mathrm{H}_{2} \mathrm{O}$ has beenbserved in PVA-Zr-PTh composites [26]. The conducting data with temperature has been fit to conductivity 
expression derived under Motts small polaron hopping model [27]. According to this model, the conductivity in the non-adiabatic region is given by

$$
\sigma=\sigma_{0} / \mathrm{T} \exp \left\{-\mathrm{E}_{\mathrm{a}} / \mathrm{K}_{\mathrm{B}} \mathrm{T}\right\}
$$

Where, $\mathrm{Ea}$ is the activation energy for small polaron hopping and $\sigma_{0}$ the pre exponential factor. The plots of $\ln (\sigma \mathrm{T})$ versus $(1 / \mathrm{T})$ were made as per Eqn (1) for all the composites and shown in Fig.7. Least square linear lines were fit to the data in the high temperature region where the data appeared linear and slopes were extracted. Using slope of each line, activation energy, Ea of the corresponding sample has been estimated.

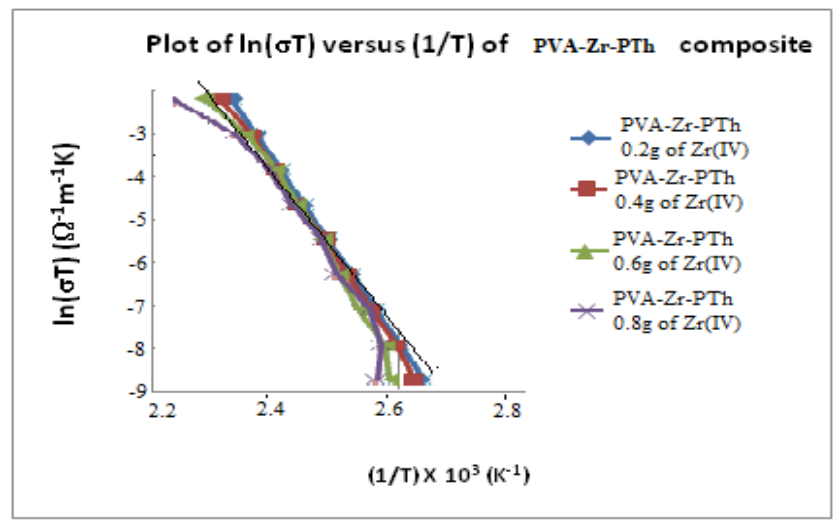

Figure 6. Plots of $\ln (\sigma \mathrm{T})$ versus $(1 / \mathrm{T})$ for various PVA-Zr-PTh composites. Solid lines are linear fits as per Mott's SPH model.

Variation of activation energy, Ea, and conductivity, $\sigma$ at $300 \mathrm{~K}$ as a function of $\mathrm{wt} \%$ of $\mathrm{ZrOCl}_{2} .8 \mathrm{H}_{2} \mathrm{O}$ are plotted in Fig.7. From the figure, it can be noted that $\mathrm{Ea}$ decreased and conductivity increased with increase of $\mathrm{wt} \%$ of $\mathrm{ZrOCl}_{2} .8 \mathrm{H}_{2} \mathrm{O}$ content. Increase in conductivity with increase in $\mathrm{Zr}(\mathrm{IV})$ content may be due to the fact that conduction process is made relatively easy by the presence of $\mathrm{Zr}(\mathrm{IV})$ grains in between PVA- PTh grains.

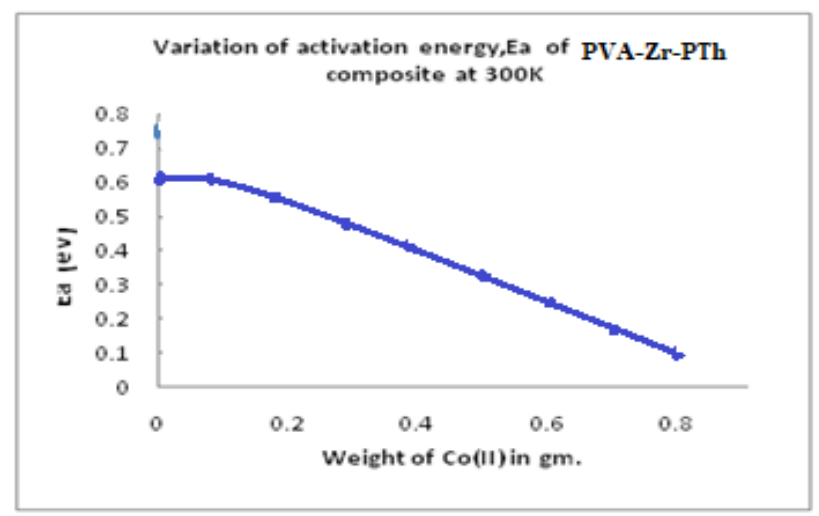

Figure 7. Variation of activation energy, $\mathrm{E}_{\mathrm{a}}$ at $300 \mathrm{~K}$ as a function of weight in gms of $\mathrm{ZrOCl}_{2} .8 \mathrm{H}_{2} \mathrm{O}$ in PVA-Zr-PTh composites. 


\section{Dielectric Properties}

The dielectric property of the material can be dependent on frequency. In this study the dielectric property of the sample is evaluated by estimating different parameters such as capacitance $C_{p}$ and RP (Relative permittivity) \& LP (loss factor) dielectric constant of the films at room temperature [28]. Figure 8. reveals the dielectric behaviour $\left(\varepsilon^{\prime}\right)$ as the variation of frequency for PVA-Zr-PTh composites with varying $\mathrm{Zr}(\mathrm{IV})$ content. It can be noticed that the dielectric constant $\varepsilon^{\prime}$ up to $3 \times 10^{5} \mathrm{~Hz}$ for all the composites is constant. Later the dielectric constant tends to increase with the increment in frequency as well as with enhancement in $\mathrm{Zr}(\mathrm{IV})$ composition. Incorporation of $\mathrm{Zr}(\mathrm{IV})$ eventuated in significant increment in dielectric constant of sample.. The variation in the dielectric constant is generally specified to the concentration of $\mathrm{Zr}^{4+}$ ions within the composites. Further the increment in dielectric constant can also be specified to increase in AC conductivity of the composites. This indicates that better the dielectric constant, higher is the capability of composites to store electric energy[29].

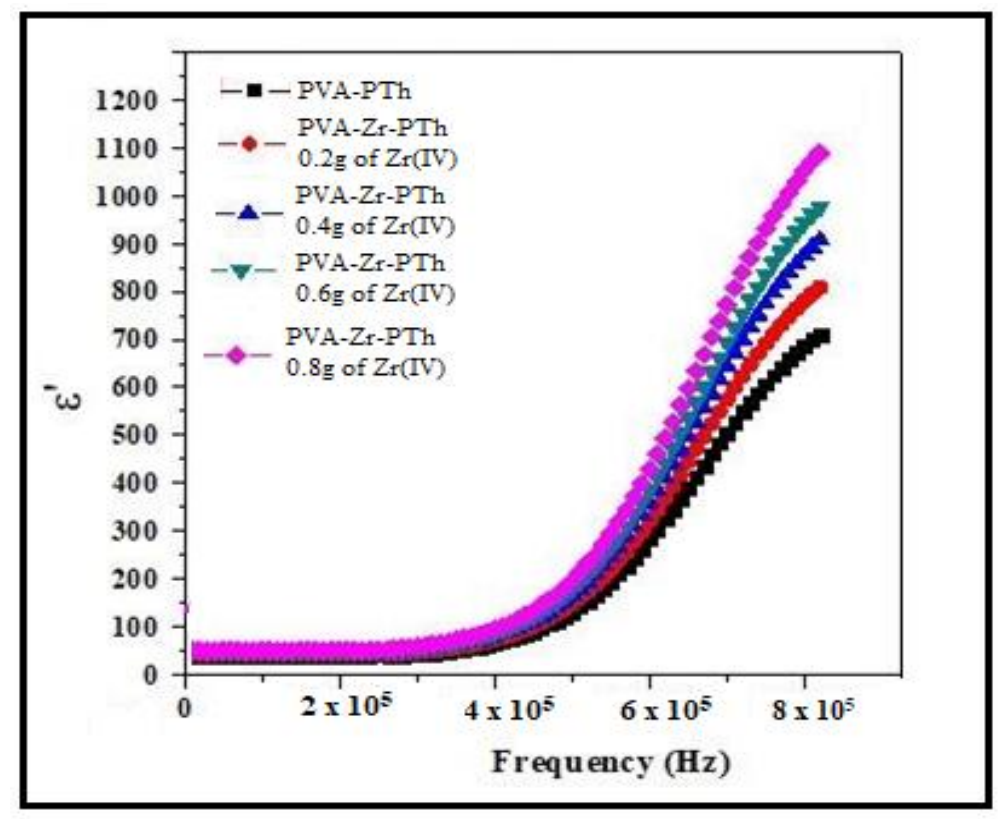

Figure 8. Plot of Dielectric Constant $\varepsilon^{\prime}$ for PVA-Zr-PTh Composites at different frequencies for varying $\mathrm{Zr}(\mathrm{IV})$ content.

\section{CONCLUSION;}

Polyvinyl alcohol-Zr-polythiophene (PVA-Zr-PTh) composite polymer films were prepared by chemical polymerization. The X-ray analysis showed an amorphous structure of the produced films after complexation of PVA/PPY with $\mathrm{ZrOCl}_{2} .8 \mathrm{H}_{2} \mathrm{O}$ as filler. After complexation with fillers $\mathrm{ZrOCl}_{2} .8 \mathrm{H}_{2} \mathrm{O}$ salt range from $0.0,0.2,0.4,0.6$ and $0.8 \mathrm{~g}$, the PVA-Zr-PTh composite samples show intense and narrow peaks at 
peaks at $25.20^{\circ}$ and $27.32^{\circ}$ with additional diffraction peaks at $27.35^{\circ}$ $29.26^{0}, 32.42^{0}, 36.43^{\circ}, 42.23^{\circ}, 47.26^{\circ}, 49.59^{\circ}, 52.32^{\circ}$ and $54.25^{\circ}$ and are (100) (100) (100) (110) (110) (111) (111) (113) (200) plane orientation of Zr particles for the $0.8 \mathrm{~g}$ of zirconyl chloride as dopant. The presence of these additional peaks is a clear evidence of the $\mathrm{Zr}^{4+}$ substitution in PVA/PTh blend and complexation through oxygen of $-\mathrm{OH}$ groups of PVA via deprotonation and sulphur of thiophene ring The FTIR spectrum exhibited characteristic peak at $3469 \mathrm{~cm}^{-1}$ due to $\mathrm{O}-\mathrm{H}$ stretching frequency of PVA/ PTh blend, but in the IR spectra of PVA-Zr-PTh composites films this absorption band was absent in all composite films of PVA-Zr-PTh due to coordination of $\mathrm{OH}$ group of PVA to $\mathrm{Zr}^{4+}$ ion via deprotonation. The SEM analysis shows that the samples become structurally more ordered with the increase in Co(II) concentration. The formation of these ordered structures supports the earlier conclusions on the basis of the XRD studies The SEM images showed that the particle size decreased by complexation with filler at $(0.0-0.6 \mathrm{~g}$ of $\mathrm{Zr}(\mathrm{IV}))$ where excess addition of filler restricted the growth of polymerization process of PVA/PTh and high agglomeration was observed for the rest samples ( $0.8 \mathrm{~g}$ of $\mathrm{Zr}(\mathrm{IV})$ ) with high content of filler due to the formation of very fine nanoparticles. The UV-VIS spectra provide evidence for the formation of metal-polymer complex. Also, the optical properties showed that the pure PVA/PPTh has one optical absorption edge, while PVA/PTh doped with $\mathrm{ZrOCl}_{2} .8 \mathrm{H}_{2} \mathrm{O}$ have three optical absorption edges. The increase in conductivity with increase in $\mathrm{Zr}(\mathrm{IV})$ concentration up to $0.8 \mathrm{~g}$ of $\mathrm{ZrOCl}_{2} .8 \mathrm{H}_{2} \mathrm{O}$ has been observed in PVA-Zr-PTh composites. it can be noted that $\mathrm{Ea}$ ( activation energy) decreased and conductivity increased with increase of $\mathrm{wt} \%$ of $\mathrm{ZrOCl}_{2} .8 \mathrm{H}_{2} \mathrm{O}$ content. The dielectric constant tends to increase with the increment in frequency as well as with enhancement in $\mathrm{Zr}(\mathrm{IV})$ composition.

\section{ACKNOWLEDGEMENTS}

We are thankful to Poojya Dr. Sharanbasvappa Appa, President Sharanbasveshwar Vidya vardhak Sangha, Kalaburagi, Prof. Anilkumar Bidve, Registrar, and Registrar(Eval) Dr. Lingaraj Shastry, Dean, Dr.Basavaraj Mathapathi and Dr. Laxmi Patil Sharnbasva University Kalaburagi, Karnataka, for their constant support and encouragement during the process of carrying out this work.

\section{REFERENCES:}

[1] Wallace G G, Teasdale P R, Spinks G M and Kane-Maguire L A, 2008, Conductive electroactive polymers: intelligent polymer systems, third edn (New York: CRC Press)

[2] Antolini E,2009, Carbon supports for low-temperature fuel cell catalysts, Appl. Catal. B: 88, 1-24.

[3] Roncali J, 1992 ,Conjugated poly (thiophenes): synthesis, functionalization, and applications, Chem. Rev. 92711

[4] Kattimani J, Sankarappa T, Praveenkumar K, Ashwajeet J and Ramanna R 
2014 Int. J. Adv. Res. Phys. Sci. 117

[5] Lee J M, Lee S J, Jung Y J and Kim J H, 2008, Fabrication of nano-structured polythiophene nanoparticles in aqueous dispersion, Curr. Appl. Phys., 8659

[6] Sulub R, Martinez-Millan W and Smit M A 2009, Study of the catalytic activity for oxygen reduction of polythiophene modified with cobalt or nickel, Int. J. Elec-trochem. Sci. 41015

[7] Schopf G and Koßmehl G 1997, Polythiophenes-electrically conductive polymers

Adv. Polym. Sci. 129, 3.

[8] Tsakova V 2008, How to affect number, size, and location of metal particles deposited in conducting polymer layers, J. Solid State Electrochem. 121421

[9] Gomez-Romero P 2001, Hybrid organic-inorganic materials in search of synergic activity, Adv. Mat. 13163

[10] Paoli M A D, Waltman R .J., Diaz A F., Bargon J., (1984). Conductive composites from poly (vinyl chloride) and polypyrrole J. Chem. Soc., Chem. Commu. 15, 1015-1016.

[11] Lindsey S E, Street G B., (1984). Conductive composites from poly(vinyl alcohol) and polypyrrole Synth. Metal. 10,1, 67-69.

[12] Ege S. N., Organic Chemistry. The University of Michigan, Ann Arbor, (1989),361.

[13] Sweeting O. J., The Science and Technology of Polymer Films. Interscience Publishers, Newyork.(1968.)

[14] Sun Z., Sun Y., Yang Q., Wang X., Zheng Z.,(1996), IR spectral investigation of the pyrolysis of polymer precursor to diamond-like carbon. Surf. Coat Technol. 79,108.

[15] El-Tantawy F, Abdelkader K M, Kane Ko F, Sung Y K. (2004), Physical properties of

CdS-poly (vinyl alcohol) nanoconducting composite synthesized by organosol techniques and novel application potential, Eur. Polym. J. 40, 415.

[16] Huang S J, Lee H K., Kang, W H. (2005), Proton Conducting Behavior of a Novel Composite Based on Phosphosilicate/Poly (Vinyl Alcohol), J. Korean. Ceram. Soc. $42,77$.

[17] Bhargav P B, Mohan V M., Sharma A K., Narasimha Rao V V R, (2007), Structural, Electrical and Optical Characterization of Pure and Doped Poly (Vinyl Alcohol) (PVA) Polymer Electrolyte Films., Int. J. Polym. Mater .56, 579.

[18] S A Waghuley, S M Yenorkar, S S Yawale and S P Yawale,(1984), Application of chemically synthesized conducting polymer-polypyrrole as a carbon dioxide gas sensor, Sens. Actuators B, 128,366.

[19] V.N. Shevchuk, Yu.N. Usatenko, P.Yu. Demchenko, O.T. Antonyak and R.Ya Serkiz., (2011) Nano- and micro-size $\mathrm{V}_{2} \mathrm{O}_{5}$ structures Chem. Met. Alloys, 4, 67. 
[20] F. Samir, M. Morsli, J. C. Bernède, A. Bonnet, S. Lefrant,(1998), X-ray photoelectron spectroscopy of polythiophene-polystyrene composites, Journal of Applied polymer Science, 10,1839.

[21] K. Praveenkumar, T. Sankarappa, Jyoti Kattimani, G Chandraprabha, J.S. Ashwajeet and R.Ramanna, (2015), 2nd International Conference on Nanotechnology, 2-3, 695.

[22] Horák Daniel, Bohuslav Rittich and Alena Španová,. Progress in Colloid and Polymer Science, 124, ( 2004),77-81.

[23] Abdelazeez M, Abdelrazek E M, (2007). Effect of dopant mixture on structural, optical and electron spin resonance properties of polyvinyl alcohol, Physica B.390,1-2,1-9,

[24] El-Shahawy M A (1993), Spectral changes of co-doped PVA films in relation to their structures, Polym. Bull. 31,199.

[25] Zidan H M, Tawansi A, Abu-Elnader M, ( 2003), Miscibility, optical and dielectric properties of UV-irradiated poly(vinylacetate) /poly(methylmethacrylate) blends, Physica B. 339, 78.

[26] Murri R, Schiavulli L, Pinto N, Ligonzo T, (1992)., Urbach tail in amorphous gallium arsenide films, J. Non-Cryst. Solids., 139, 60

[27] P Chitra, A Muthusamy, R Jayaprakash, (2015), Structural, magnetic and dielectric properties of polyaniline $/ \mathrm{MnCoFe}_{2} \mathrm{O}_{4}$ nanocomposites, J. Magn. Magn. Mater., 396, 113.

[28] L Yang J. Qiu H Ji, K. Zhu J. Wang, (2014), Enhanced dielectric and ferroelectric properties induced by $\mathrm{TiO}_{2} @$ MWCNTs nanoparticles in flexible poly(vinylidene fluoride) composites Composites: Part A 65, 125-134.

[29] Saxena Dinesh, Dwivedi Vivek and Mishra Pankaj Kumar,(2013), Dielectric study of polyaniline in Frequency range $100 \mathrm{~Hz}$ to $500 \mathrm{~Hz}$ at temperature $20^{\circ} \mathrm{C}$ and $30^{\circ} \mathrm{C}$, Research Journal of Chemical Sciences., 3(2),16-19. 
